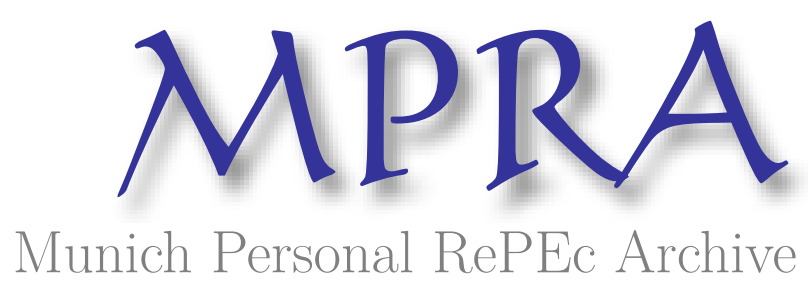

\title{
Forensic accounting theory
}

Ozili, Peterson K

12 June 2020

Online at https://mpra.ub.uni-muenchen.de/102566/

MPRA Paper No. 102566, posted 26 Aug 2020 11:32 UTC 


\title{
Forensic accounting theory
}

\author{
Peterson K. Ozili
}

\begin{abstract}
This article presents a forensic accounting theory. Forensic accounting theory is an explanation of why and how the choice of methods and techniques used to detect creative accounting or fraudulent manipulations in financial reporting, and the outcome of using such methods or techniques, depends on the accounting and non-accounting decisions taken into consideration by the forensic accountant or investigator. The forensic accounting theory developed in this paper is useful to both practitioners and academics, and the resulting contribution to accounting theory and forensic science are useful to the problem-solving process in the global fight against financial crime.
\end{abstract}

Keywords: fraud, forensic accounting, financial reporting, fraud detection, forensic accounting theory, accounting, financial accounting, forensic science, accounting education, forensic accountant.

JEL Classification: M41, M42, M48

This Version: January, 2020.

Published in: Finance, Insurance and Risk Management Theory and Practices, Vol. 1, Emerald. 


\section{Introduction}

A forensic accounting theory is an explanation for observed forensic accounting practices. Past and recent accounting scandals in financial and non-financial firms have shown that expertise in forensic accounting is crucial to detect financial fraud that originates from a firm's financial accounting process. The emerging innovations in financial fraud schemes, and the frequent changes in accounting methods and policies by firms in the preparation of financial reports have made fraud detection become a complicated process in recent times. For this reason, a combination of skill, knowledge, experience and ability to pay 'attentionto-details' will be the major attribute of a successful forensic investigator in these times.

These observations require some new thinking in the forensic accounting literature in explaining why and how certain skills and methods are used to detect fraud, the decisions regarding the materiality of the findings, and the precautions taken when reaching conclusions from the fraud detection process. A forensic accounting theory can provide some explanations! As new academics emerge and are eager to understand forensic accounting, either as a branch of accounting or as a branch of forensic science in a fast changing world where sophisticated innovations in creative accounting have increased rapidly in the business sector, it is needful to remind ourselves that the forensic accounting as a field of study may become porous and disconnected if there are no set of theories or theory that explain observed forensic accounting practices. Such theory is needed to change how we think about forensic accounting practice, and to advance our understanding of forensic accounting.

Of course, no theory is perfect and I have been careful to reduce the degree of abstraction in the forensic accounting theory developed in this article in order to increase the relevance of this theory to both academics, practitioners and policymakers. Although this theory can be expanded into large volumes of texts, I have presented an abridged and concise version of the theory due to space constraints. I would gladly welcome any requests for an extended theory. I hope the reader would find the theory useful for intellectual discourse and for future research in forensic accounting.

The theory developed in this article makes a contribution to the forensic science literature and to the accounting theory literature. By developing the forensic accounting theory, I present a new and comprehensive statement of how the choice of forensic detection methods and techniques are made, and how the findings from forensic detection activities are interpreted. I argue that the forensic science literature - whether academic, policy or practice - can use the forensic accounting theory perspective to provide believable explanations for fraud detection objectives and outcomes. In relation to the accounting theory literature, I present some hypotheses or frameworks that can be used in the study of forensic accounting as a branch of accounting. 
Finally, the term 'forensic accountant' and 'forensic investigator' are used interchangeable in this article. The term 'forensic investigator' is rather preferred because it recognizes that not all forensic investigators are accountants. Forensic investigators may be accountants, economists, actuary, lawyers, psychologists, etc. Therefore, using the term 'forensic investigator' is a broader term that encompass the wide range of professionals involved in forensic investigation.

The remainder of the paper is organized as follows. Section 2 presents a review of the forensic accounting literature. Section 3 discuss the forensic accounting theory. Section 4 discuss the accounting decisions in forensic accounting theory. Section 5 discuss the non-accounting decisions in forensic accounting theory. Section 6 concludes.

\section{Literature review}

There are several definitions of forensic accounting in the literature. For instance, forensic accounting has been defined as the application of financial skills and investigative mentality to unresolved issues conducted within the context of the rules of evidence (Bolgna and Linquist, 1995). Forensic accounting is also defined as the application of accounting and auditing, financial and investigative skills, to unsettled issues conducted within the context of the rules of evidence (Arokiasamy and Cristal-Lee, 2009; Ozkul and Pamukc, 2012). Forensic accounting may also be defined as the application of auditing methods, techniques or procedures to resolve legal issues that require the integration of investigative, accounting, and auditing skills (Arokiasamy and Cristal-Lee, 2009; Dhar and Sarkar, 2010). Forensic accounting may also be defined as the process of gathering, interpreting, summarizing and presenting complex financial issues in a clear, succinct and factual manner often in a court of law as an expert (Howard and Sheetz, 2006; Stanbury and Paley-Menzies, 2010).

Some scholars agree that forensic accounting can help to uncover fraud (Singleton, 2010; Silverstone et al, 2004), but such consensus depends on how fraud is defined. Some studies define fraud and identify the motivations to commit fraud (Rezaee, 2005; Crumbley, 2003; Zahra et al, 2005; Ozili, 2015; Calavita et al, 1997). Fraud in financial reporting may be defined as a deliberate attempt by corporations to deceive or mislead users of published financial statements, especially investors and creditors, by preparing and disseminating materially misstated financial statements (Rezaee, 2005: p.279). Fraud can be committed by employees, former employees and outright outsiders (Crumbley, 2003; Zahra et al, 2005; Ozili, 2015), and there is a general consensus that fraud involves the intentional alteration or manipulation of material financial records and supporting documents (Ozili, 2015). Fraud schemes vary in scope and context, and some types of fraud are industry-specific (Calavita et al, 1997, Ozili, 2020). 
The common motivations to commit fraud in the literature are: the pressure to meet personal needs, social needs and economic needs, and the need to meet compensation-based targets (Johnson et al, 2003; Denis et al, 2006; Hernandez and Groot, 2007; Lie, 2005; Burns and Kedia, 2006; Erickson et al, 2000). The fraud triangle is a framework widely used in the literature to describe the motivation to commit fraud and how fraud is perpetuated (Schuchter and Levi, 2016). The fraud triangle shows that individuals who commit fraud follow a triangular sequence which means that there is a need that must be met, there will be some opportunity to meet the need through illegal means, and the ability to rationalize why the fraud should be committed (Ozili, 2015; Schuchter and Levi, 2016). Other studies have expanded the fraud triangle to include additional fraud motivators (see Dorminey et al, 2010; Ozili, 2015; Lokanan, 2015; Huber, 2017; and Free, 2015).

The literature also highlight the important skills needed to be a forensic investigator. The core skills are strong analytical abilities, written and verbal communication skills, creative mind-set and business acumen (Messmer, 2004); critical and strategic thinking, auditing skills, investigative ability, synthesis of results and thinking like the wrong-doer, critical and strategic thinking, effective written communication, effective oral communication, and investigative intuitiveness (Davis et al 2010); in-depth knowledge of financial statements, the ability to critically analyse them and a thorough understanding of fraud schemes (Ramaswamy, 2005).

Other studies emphasize the need for forensic accounting to be incorporated in the accounting curriculum taught in tertiary institutions or universities (e.g. Rezaee and Burton, 1997; Peterson and Reider, 1999, 2001; Rezaee, 2002; Crumbley et al, 2003). Buckhoff and Schrader (2000) argue that incorporating forensic accounting as a course of study in the accounting curriculum benefits three major stakeholders in accounting education which are the academic institutions, students and employers of accounting graduates. These studies show that the study of forensic accounting requires broad multi-disciplinary knowledge, particularly, knowledge of business activities, human behaviour (or psychology) and a good working knowledge of the legal system, and that students of forensic accounting will be able to interact with other disciplines in order to be well knowledgeable about forensic accounting.

Some studies identify some issues in the literature such as the "false positive" problem (i.e., reported fraud red flags that turn out to be false). This problem occurs mostly because forensic investigators tend to associate fraud symptoms with actual fraud. In practice, we know that not all fraud red-flags turn out to be actual fraud (Albrecht and Romney, 1986, Ozili, 2015). Another issue is the cost and benefit of undertaking a forensic investigation exercise. Investigation into every reported fraud case may be too costly, for this reason, not all reported fraud cases will be given top priority coupled with the unwillingness to commit 
funds to investigate financial crime that do not lead to the recovery of proportionate proceeds from financial fraud.

\section{Forensic accounting theory}

Forensic accounting theory looks at how the accounting and non-accounting decisions made at the start, during or at the end of the investigation process affects the choice of forensic detection methods and techniques used, and the interpretation of the findings of forensic investigation. Forensic accounting theory states that the techniques and methods used to detect fraud reflect the accounting and non-accounting decisions that were taken into consideration by the forensic investigator. In other words, the main premise of forensic accounting theory is that the choice of forensic detection methods is not merely a result of the forensic investigator's experience, skills or knowledge but rather depends on the accounting and nonaccounting considerations made by the forensic investigator at the start, during, or at the end of fraud detection process.

Thus, forensic accounting theory suggest that the choice of methods or techniques used to detect creative accounting or manipulations in financial reporting, and the outcome of using such methods or techniques, reflect the accounting and non-accounting decisions that were taken into consideration by the forensic accountant or investigator.

Some working assumptions

- A humane objective of a forensic investigation exercise is to identify and uncover unresolved issues, and recommend corrective actions that discourage such behavior from occurring again.

- Such corrective actions may include the imposition of fines, imprisonment, etc.

- The outcome and findings of a forensic investigation exercise should not lead to the collapse of the convicted firm or the death of the convicted individual. Without this assumption, forensic investigators may seek the downfall of the corporation or the individual they are investigating for criminal suspicion. Therefore, this assumption is crucial because it eliminates the personal judgmental bias of the forensic investigator, and prevents the personal bias of forensic investigators from interfering with the forensic investigation

Given the assumptions above, let's develop some hypotheses that explain the accounting and nonaccounting considerations that influence the choice of methods and outcomes of a forensic investigation activity. 


\section{The accounting decisions}

\subsection{Materiality hypothesis}

The materiality hypothesis of forensic accounting theory states that forensic investigators will use forensic detection methods that help to determine whether the unresolved case is material or immaterial under legal and regulatory rules. After a case has been reported for investigation and the case involves financial reports or financial statements that are perceived to be materiality misstated, it is in the best interest of the forensic investigators to use forensic detection methods that reveal the true nature of the case, and the actual monetary value involved in the case, from which a determination can be made as to whether the actual monetary value is material or not.

This is important because the victim or whistle-blower that reported the case can overstate or understate the materiality of the reported case especially when it involves accounting fraud. To avoid being misled by the victim or whistle-blower, forensic investigators should conduct their own investigation to determine whether the case is truly material or significant for further investigation. If the goal is to determine the materiality of the case, forensic investigators are more likely to choose forensic detection methods or procedures that increase the likelihood of identifying the material aspects of the case. One criticism that can be made against the materiality hypothesis is that forensic investigators can deliberately use certain forensic detection methods that overstate or understate the materiality of the case especially when there is conflict of interest between the alleged fraudster and the forensic investigator.

H1: Forensic investigators choose forensic detection methods that determine whether the case is material or immaterial for investigation.

\subsection{Ability signaling hypothesis}

\subsubsection{Hypothesis}

The ability signaling hypothesis states that forensic investigators will use sophisticated forensic detection methods that signal their superior forensic accounting ability and their ability to uncover unresolved issues. In environments where people do not trust investigators and do not trust the integrity of their findings, forensic investigators will be under pressure to prove their worth! Investigators in such environments will have strong incentives to use sophisticated techniques to prove their worth and to prove their superior ability to outsiders. For instance, to uncover accounting fraud, forensic investigators can use their knowledge of sophisticated accounting techniques, their specialist knowledge in accounting practice and their expert 
knowledge in the application of accounting standards coupled with their experience in forensic investigation. Using such sophisticated methods give forensic investigators an opportunity to differentiate themselves from their peers and competitors in the crime detection industry, and it can increase their credibility and reputation in the industry as well.

To illustrate the ability signaling hypothesis, consider this example. In recent years, some big-four audit firms have had fraudulent scandals that were serious cases although the audit firms were able to regain their reputation through their ability to signal their superior capability in financial statement audit in the industry. In 2019, KPMG was involved in a big scandal. ${ }^{1}$ A leader of the Public Company Accounting Oversight Board Inspections (PCAOBI) provided KPMG employees with confidential information on some of PCAOB's 2016 inspection selections to help KPMG alter the audit reports to favour KPMG's clients. This was a huge scandal to KPMG. KPMG subsequently published some industry reports that contained positive news for the industry which helped to weaken the effect of the scandal on the firm. The positive news was contained in its "2019 Global CEO Outlook" report and the "Growth Promise Indicators: 2019 report". This describes how firms that have a fiduciary investigative duty can use their superior ability to signal and reinforce their position in the industry despite being faced with scandals and lack of public trust.

H2: Forensic investigators choose forensic detection methods that signal their superior forensic accounting ability to outsiders.

\section{Non-accounting decisions}

\subsection{Bonus contract hypothesis}

\subsubsection{Hypothesis}

The bonus contract hypothesis states that, if the compensation or bonus to the forensic investigator is attached to how thorough and successfully forensic investigators are in uncovering unresolved issues when investigating suspected financial misstatements or financial crime, it is in the best interest of forensic investigators to use specific forensic detection methods, materiality assumptions and interpretations that increase the likelihood of uncovering unresolved (or suspected) financial crime or misstatements, which in turn would improve the compensation to the forensic investigator. Forensic investigators with bonus

\footnotetext{
${ }^{1}$ https://www.complianceweek.com/accounting-and-auditing/ex-pcaob-leader-gets-prison-time-for-role-centralto-kpmg-scandal/27877.article https://www.accountancydaily.co/former-us-kpmg-director-jailed-over-pcaob-tip-offs
} 
contracts are more likely to choose forensic detection methods or procedures that increase the likelihood of uncovering unresolved issues especially those relating to financial crime. Furthermore, if detecting actual fraud is the benchmark for assessing the performance of the forensic investigator, the forensic investigator will have stronger incentives to use specific forensic methods, procedures and choices that increase the probability of receiving the promised compensation that depend on the successful detection of actual fraud. For the purpose of empirical testing, the bonus contract hypothesis can be stated as:

H3: the presence of bonus contracts for forensic investigators lead to higher likelihood of resolving financial fraud cases

\subsubsection{Some reflection involving two scenarios}

The relationship between the bonus contract to a forensic investigator and the likelihood of uncovering unresolved cases is not necessarily linear! Let's use two scenarios to illustrate this. In the first scenario, consider a forensic investigator who receives a fixed compensation or salary that is independent of the outcome of the forensic investigation he or she participate in. The forensic investigator is entitled to a fixed compensation, and is also promised an additional compensation if he or she is able to uncover one or more unresolved cases. If the forensic investigator perceive that the outcome of the forensic detection activity may fall below the minimum level required for payment of the promised compensation, the forensic investigator will have strong incentives to withdraw from the forensic investigation if he or she believe that the likelihood of receiving the promised bonus is low or that no bonuses will be paid at the end of the investigation if they are unsuccessful in resolving the case. The forensic investigator will prefer to settle for the fixed compensation and refuse the bonus contract since taking the risk won't be worth it. This scenario shows a type of non-linearity in the relationship between bonus contracts and the likelihood of uncovering unresolved cases such as cases involving financial misstatements or suspected financial crime.

In the second scenario, consider a forensic investigator that does not receive a fixed compensation or salary. The forensic investigator relies solely on a promised bonus contract which is dependent on his or her ability to uncover the unresolved case(s). If the forensic investigator perceive that the outcome of the forensic examination may fall below the minimum level or expectation required for payment of the promised bonus, the forensic investigator will have some incentive to negotiate and renegotiate for a bonus contract that is commensurate with the nature of the case, the complexity of the case and the risk involved in the case, in order to increase the likelihood of resolving the case which would also increase the likelihood of receiving the bonus contract. This scenario shows another type of non-linearity in the relationship between bonus contracts and the likelihood of uncovering unresolved cases. It shows that forensic investigators have incentives to negotiate and renegotiate their bonus contracts to a higher or lower amount in order to increase 
the likelihood of receiving the promised bonus plan. Such adjustments may create a kink (a curve in a straight line) in the linear relationship between relationship between bonus contracts and the likelihood of uncovering unresolved cases.

\subsubsection{Empirical testing of the bonus contract hypothesis}

The bonus contract hypothesis may be difficult to test due to lack of information about the bonus contract or bonus payments made to forensic investigators who were successful in the cases they handled or participated in. Some countries like the U.S. have disclosure laws that permit the legal disclosure of bonus payments made to forensic investigators - in the US for instance such law exist as the 'freedom of information' act, while other countries or environments do not have laws that permit disclosure of such information. For the purpose of empirical testing, a rule of thumb that can be used as a proxy to measure "bonus contract" when the actual bonus contract is not observable is to use a 15\% markup of the fixed (and current) compensation (or salary) of the forensic investigator. This rule of thumb is valid under the assumption that the salary of tenured forensic investigators or accountants is publicly available or can be obtained legally from their employers. Intuitively, the $15 \%$ salary markup means that the total monetary value of the bonus contract awarded to a successful forensic investigator is at least $15 \%$ of the fixed (or current) salary of the forensic investigator.

\subsection{Anonymity hypothesis}

\subsubsection{Hypothesis}

The anonymity hypothesis states that, if the outcome of a forensic investigation may threaten the personal security of forensic investigators, it is in the best interest of forensic investigators to use specific forensic detection methods that hide their identity even if using such methods may decrease the likely of resolving the case. Such methods include the use of questionnaire, letters, text messaging, and audio interviews through phone calls. These methods do not allow the accused to see or meet the investigator in person, and these methods work well especially when investigating financial crimes and fraudulent misstatements by individuals or firms affiliated with criminal gangs, drug cartels and related groups.

The anonymity hypothesis argues that the personal security of the forensic investigator takes precedence over the need to successfully resolve the case at hand. This is a reasonable argument given the long history of decades where associates of convicted fraudsters have either attacked or killed both the whistleblower and the investigator. For instance, in the last two decades, the mafia and cartels in Mexico assassinated over 40,000 individuals (Sullivan, 2011), among those killed were whistleblowers and investigators of criminal 
cases who helped to arrest gang members that have now been incarceration for life (Bunker, 2011). In other cases, the political elite declined to prosecute law breakers and criminal organizations instead they punished whistleblowers through secret assassinations and unjust imprisonments (Reding, 1997). These observations are quite common in third world countries and in some developed countries, and forensic investigator are aware of these issues! As a result, forensic investigators who are civilians are unwilling to risk their lives for fear of being targeted for reprisal.

Ideally, one would expect that the forensic investigator would withdraw from investigating a case if threat to life is anticipated. But the tendency to withdraw from the case is reduced if the usual monetary benefits that come with successful forensic investigation are maintained and significantly increased, such as receiving a fixed salary, promise of higher bonuses, being promoted, access to multiple forensic methods and tools, and greater autonomy. Therefore, all other things being equal, forensic investigators that believe that their personal security may be at risk and still want to continue with the case, are more likely to continue with the forensic investigation by choosing forensic detection methods or procedures that hide their identity. For the purpose of empirical testing, the anonymity hypothesis can be stated as:

H4: Forensic investigators will choose forensic methods and procedures that hide their identity when they anticipate a threat to life

\subsubsection{Empirical test of the anonymity hypothesis}

The anonymity hypothesis is easy to test empirically. Assume the researcher is interested in interviewing forensic investigators that have previously handled one or more cases involving fraud committed by criminal organizations. For practical purposes, the empirical researcher can use questionnaires that require forensic investigators to indicate whether they had concerns about disclosing their identity when there is perceived threat to life, and whether such concern influenced the choice of forensic methods used during the investigation. Using the data collected from the questionnaires or interviews, the researcher can perform some correlation analyses to determine whether there is a significant association or correlation between forensic investigators' anonymity and the successful completion of the forensic investigation. A causation analysis can also be performed. This involves using regression estimation to estimate whether the being successful in forensic investigations is a function of the anonymity of forensic investigators and other relevant explanatory factors that affect the success of forensic investigations. 


\subsection{Collapse avoidance hypothesis}

\subsubsection{Hypothesis}

In the past, many firms witnessed corporate scandals and made some risky business decisions that led to their collapse, forcing the firms to windup. Examples of such firms are Enron, WorldCom, Lehman brothers etc. In forensic practice, the goal of forensic investigations is not to see the downfall of an accused individual or corporation. Rather, our job is to uncover unresolved cases. Only the law through the courts should decide whether the firm should be winded-up or whether an accused individual should be punished for the financial crimes committed.

At the start of major forensic investigation, there is usually an opening discussion meeting with the management of the firm and the forensic investigators. If the forensic investigators inform the management of the firm that the purpose of the investigation is to uncover some unresolved issues for corrective purposes, the management of the firm will be willing to cooperate with the forensic investigators during the course of the investigation. On the other hand, if the forensic investigators inform the management of the firm that the purpose of the investigation is to uncover an unresolved issue, and to discipline the firm if found guilty, the management of firm will interpret this to mean that the firm could face the highest possible legal consequences if found guilty such as liquidation or winding up, and the management of the firm may be unwilling to cooperate with the forensic investigators during the course of the investigation and can frustrate the investigation process. Therefore, it is in the best of interest of forensic investigators to assure and reassure the management of the firm that the outcome of ongoing investigation will only lead to correct the wrongdoing, not to wind up the company. Also, at the end of a forensic investigation, the findings from a forensic investigation activity should be devoid of statements that suggest that the accused firm should be windup because of their actions. This is because the consequence of committing fraud should have both a legal penalty component and a corrective component, and the firm (or individual) involved need to remain a going concern (or alive) for it to learn to act ethically in the future.

Consider the case where a firm engaged in fraudulent financial reporting by under-stating its profits which enabled it to illegally pay very low corporate taxes in the last 15 years and moved its profits to another country. The forensic accountant will estimate the actual tax amount that should have been paid legally, and would conclude that the firm misstated its profit in the financial statements to evade taxes. If the estimated monetary value of the unpaid taxes exceeds the current total assets of the firm, the penalty or fine to be imposed on the firm should not lead to the bankruptcy of the firm; rather, the culprits should serve the legal consequence, or the payment of fines, if any, should be structured in a way that allow the firm to pay fully for committing the crime which would serve as a deterrent from engaging in such behaviour in the 
future. I call this the collapse avoidance argument which argue that forensic investigators that have multiple forensic methods to use should be aware that the objective of forensic investigation is not to wind-up the company if found guilty but to provide evidence to support the legal process to bring about corrective behavior in the future.

H5: the goal of forensic investigation is not to bring about the collapse of the entity being investigated.

\subsubsection{Empirical test of the collapse avoidance hypothesis}

The collapse avoidance hypothesis is easy to test empirically using public information about companies that were indicted for financial crime or financial fraud. The empirical researcher can determine the ratio of indicted (or convicted) companies that collapsed as a result of the outcome of forensic investigation compared to the total number of companies that were indicted, or under investigation, for financial crime or financial fraud during some defined period.

Let's derive the collapse avoidance ratio.

Assume $\mathrm{N}=$ number of companies that were investigated and wind-up as a result of the outcome of forensic investigation in a defined period say 2010; $\mathrm{V}=$ total number of companies that were investigated in 2010; $\mathrm{S}=$ number of companies that were investigated but did not wind-up after the investigation in 2010 .

$=\mathrm{N} / \mathrm{V}$, where $\mathrm{N} \leq \mathrm{V}$, and $\mathrm{V} \geq 0$, and

$=\mathrm{S} / \mathrm{V}$, where $\mathrm{S} \leq \mathrm{V}$, and $\mathrm{V} \geq 0$

$=(\mathrm{S} / \mathrm{N}) /(\mathrm{N} / \mathrm{V})$ is equivalent to $\mathrm{S} / \mathrm{N}$

Therefore, the collapse avoidance ratio is expressed as $(\mathrm{S} / \mathrm{N})$, and the collapse avoidance conditionality is satisfied when $\mathrm{S} / \mathrm{N}>1$ (indicating that there should be a greater number of firms that survive the outcome of forensic investigations compared to firms that did not survive the outcome of forensic investigation). 


\section{Conclusion}

In this paper, I postulated a forensic accounting theory and derive some hypotheses in the formulation of the theory. The forensic accounting theory identified the accounting and non-accounting decisions taken into consideration by the forensic accountant or investigator during a forensic investigation exercise. The forensic accounting theory propose four hypotheses that explain the accounting and non-accounting decisions taken into consideration by forensic investigators namely: the materiality hypothesis, ability signaling hypothesis, bonus contract hypothesis, anonymity hypothesis and the collapse avoidance hypothesis.

The implication of the forensic accounting theory is that forensic accountants and investigators should consider the broader implications of their choice of forensic detection methods in the forensic investigation activity they are involved in. Forensic investigators should also be aware of their working tools and the investigative environment they thread on, taking into account the relevant accounting and non-accounting considerations as well as the diverse interests of both the forensic investigator and the firms or individuals being investigated. The forensic accounting theory developed in this paper is useful to both practitioners and academics involved in the problem-solving process for improving the integrity and quality of financial reporting and the fight against financial crime. 


\section{Reference}

Albrecht, S. and Romney, M. (1986). Red-flagging management: a validation, Advances in Accounting, 3, 323-33.

Arokiasamy, L., and Cristal-Lee. S. (2009). Forensic Accounting: Public Acceptance towards Occurrence of Fraud Detection. International Journal of Business and Management. 145-160

Bolgna, G \& Linquist, R. (1995). Fraud Auditing and Forensic Accounting: New Tools and Technique. 2nd Ed. New York, NY: John Wiley \& Sons.

Buckhoff, T. A. \& Schrader, R. W. (2000). The Teaching of Forensic Accounting. Journal of Forensic Accounting, 1 (1), 135-146.

Bunker, R. J. (2011). Criminal (Cartel \& Gang) Insurgencies in Mexico and the Americas: What You Need to Know, Not What You Want to Hear: Testimony before the House Foreign Affairs Subcommittee on the Western Hemisphere at the Hearing 'Has Merida Evolved? Part One: The Evolution of Drug Cartels and the Threat to Mexico's Governance.'. Small Wars Journal El Centro, 86.

Burns, N., \& Kedia, B. (2006). The Impact of Performance-Based Compensation On Misreporting. Journal of Financial Economics 79 (1): 35-67.

Crumbley, D.L, Heitger, L.E and Smith, G.S. (2003) Forensic and Investigative Accounting. Chicago: CCH Incorporated.

Davis, C., Farrell, R., \& Ogilby, S. (2010). Characteristics and skills of the Forensic Accountant. American Institute of Certified Public Accountants, 11-26.

Denis, D. J., Hanouna, P., \& Sarin, A. (2006). Is there a dark side to incentive compensation? Journal of Corporate Finance, 12 (3): 467- 488

Dhar, P., \& Sarkar, A. (2010). Forensic Accounting: An Accountant's Vision. Vidyasagar University Journal of Commerce, 15(3), 93-104

Erickson, M., Mayhew, B.W., \& Felix, W.L (2000) Why Do Audits Fail? Evidence from Lincoln Savings and Loan. Journal of Accounting Research 38: 165-194.

Free, C. (2015). Looking through the fraud triangle: A review and call for new directions. Meditari Accountancy Research, 23(2), 175-196.

Hernandez, J. R., and Groot, T (2007) Corporate Fraud: Preventive Controls Which Lower Fraud Risk. Working Paper, Free University of Amsterdam. 
Howard, S. \& Sheetz, M. (2006). Forensic Accounting and Fraud Investigation for Non-Experts. New Jersey: John Wiley \& Sons Inc.

Huber, W. (2017). Forensic accounting, fraud theory, and the end of the fraud triangle. Journal of Theoretical Accounting Research, 12(2).

Johnson, S.A., H.E. Ryan, Y.S. Tian. (2003). Executive Compensation and Corporate Fraud. Working Paper. WLU/ Louisiana State University.

Lie, E. (2005). On The Timing of CEO Stock Option Awards. Management Science, 51 (5): 802-812

Lokanan, M. E. (2015, September). Challenges to the fraud triangle: Questions on its usefulness. In Accounting Forum 39 (3), pp. 201-224. Taylor \& Francis.

Messmer, M. (2004). Exploring options in forensic accounting. National Public Accountant, 5, 9-20.

Ozili, P.K. (2020). Advances and issues in fraud research: a commentary. Journal of Financial Crime, 27 (1)

Ozili, P. K. (2015). Forensic Accounting and Fraud: A Review of Literature and Policy Implications. International Journal of Accounting and Economics Studies, 3(1), 63-68.

Özkul, F. U., \& Pamukçu, A. (2012). Fraud detection and forensic accounting. In Emerging fraud (pp. 1941). Springer, Berlin, Heidelberg.

Peterson, B. K., \& Reider, B. P. (1999). Fraud Education of Accounting Students: A Survey of Accounting Educators. The National Accounting Journal, 23-30.

Ramaswamy, V. (2005). Corporate governance and the forensic accountant. CPA Journal, 75, 68-70.

Reding, A. (1997). Facing political reality in Mexico. Washington Quarterly, 20(4), 103-116.

Rezaee, Z. (2002). Forensic Accounting Practices, Education, and Certifications. Journal of Forensic Accounting, 3 (2), 207-223.

Rezaee, Z. (2005). Causes, consequences, and deterrence of financial statement fraud. Critical Perspectives on Accounting, 16(3), 277-298.

Rezaee, Z., \& Burton, E. J. (1997). Forensic Accounting Education: Insights from Academicians and Certified Fraud Examiner Practitioners. Managerial Auditing Journal, 12 (9), 479-489.

Schuchter, A., \& Levi, M. (2016). The fraud triangle revisited. Security Journal, 29(2), 107-121. 
Singleton, T. W. (2010). Fraud auditing and forensic accounting (Vol. 11). John Wiley \& Sons.;

Silverstone, H., Sheetz, M., Pedneault, S., \& Rudewicz, F. (2004). Forensic accounting and fraud investigation for non-experts (Vol. 2). Hoboken, NJ: Wiley.

Stanbury, J., \& Paley-Menzies, C. (2010). Forensic futurama: Why forensic accounting is evolving. AICPA Store, 28.

Sullivan, J. P. (2011). From drug wars to criminal insurgency: Mexican cartels, criminal enclaves and criminal insurgency in Mexico and Central America. Implications for global security.

Dorminey, J. W., Fleming, A. S., Kranacher, M. J., \& Riley Jr, R. A. (2010). Beyond the fraud triangle. The CPA Journal, 80(7), 17.

Zahra, S. A., Priem, R. L., \& Rasheed, A. A. (2005). The Antecedents and Consequences of Top Management Fraud. Journal of Management, 31(6), 803-828. 